\title{
Elastomer Composites with Enhanced Ice Grip Based on Renewable Resources
}

\author{
Nikolai Dishovski1,2*, Filis Mitkova1, Mara Kandeva3 ${ }^{3}$, Yordan Angelov², Ivan Uzunov, \\ Milcho Ivanovi,2, Dimitar Klissurski2,4 \\ ${ }^{1}$ University of Chemical Technology and Metallurgy, Sofia, Bulgaria \\ ${ }^{2}$ Ecopolymeric Systems Ltd., Sofia, Bulgaria \\ ${ }^{3}$ Technical University, Sofia, Bulgaria \\ ${ }^{4}$ Institute of General and Inorganic Chemistry, Bulgarian Academy of Sciences, Sofia, Bulgaria \\ Email: *dishov@uctm.edu
}

How to cite this paper: Dishovski, N., Mitkova, F., Kandeva, M., Angelov, Y., Uzunov, I., Ivanov, M. and Klissurski, D. (2018) Elastomer Composites with Enhanced Ice Grip Based on Renewable Resources. Materials Sciences and Applications, 9, 412-429.

https://doi.org/10.4236/msa.2018.94028

Received: March 13, 2018

Accepted: April 21, 2018

Published: April 26, 2018

Copyright (c) 2018 by authors and Scientific Research Publishing Inc. This work is licensed under the Creative Commons Attribution International License (CC BY 4.0).

http://creativecommons.org/licenses/by/4.0/ Open Access

\begin{abstract}
Slips and falls on icy surfaces can cause serious injuries of people. The primary risk factor for slipping incidents is undoubtedly the decreased friction coefficient between the shoe sole and the ice or snow surface. Nowadays environmental protection has been gaining significance and becoming highly important for the various innovation strategies. In rubber industry the concept of environmental protection is more often associated with the maximum use of elastomers and ingredients from renewable sources in the manufacture of rubber products. The aim of this work is to investigate the possibilities of using elastomers and ingredients from renewable sources-epoxidized natural rubber, silica obtained by rice husks incineration and microcrystalline cellulose-as fillers and rapeseed oil as a process additive in compositions, intended for the manufacture of soles for winter footwear having an increased coefficient of friction to icy surfaces. The tribological tests based on the coefficient of friction evaluated the adhesion of the composites to the icy surfaces at different temperatures. The complex evaluation of developed composites revealed those containing microcrystalline cellulose and biogenic amorphous silica at a 1:1 ratio as the most suitable for making footwear soles because of the best combination of physico-mechanical properties and coefficient of friction.
\end{abstract}

\section{Keywords}

Elastomer Composite, Epoxidized Natural Rubber, Biogenic Amorphous Silica, Microcrystalline Cellulose, Tribological Measurements

\section{Introduction}

Slips and falls are quite common on icy surfaces and can cause serious injuries. It 
is believed that slipping accounts for $16 \%$ of all incidents and $43 \%$ of all fall incidents in the Scandinavian countries [1]. For instance, in Finland nearly 50,000 pedestrians each year receive injuries resultant from slipping on icy or snowy surfaces which lead to medical consultation [2]. The primary risk factor for slipping incidents is undoubtedly the decreased friction coefficient between the shoe sole and the surface beneath it. The facts described above indicate a significant public health issue associated with the adhesion of the footwear to the icy surface. A number of authors have done research in the particular area.

Derler et al. [3] examine the influence of temperature on adhesion by combining friction and hardness measurements. Groonqvist and Hirvonen have studied the behavior of 49 types of winter shoes on ice and snow [4]. According to their assessment, the nature of the material from which the sole is made and its firmness are the crucial factors determining the adhesion on dry ice. Higher probability of slipping on melting or wet ice has been confirmed by Gao et al. [5], who has also examined the effect that the sole has on the friction coefficient. The results show that artificially induced wear of the sole increases the slip resistance on hard ice, but not on melting ice. As seen from those studies, the chemical nature of the composite used to make the sole and its hardness (the latter depends on the former) are major determinants of slip resistance. Undoubtedly, the dynamics (kinetic) coefficient of friction (COF) of the sole to the icy surface is of particular importance for this resistance. As established, $\mathrm{COF}$ depends on the roughness and structure of the material for soles production, in the case smoother surfaces and softer materials have a higher grip [5]. The grip on ice is significantly lower than on wet surfaces, due to the hardening of the composite at lower temperatures. Therefore, materials whose hardness increase is limited or null at low temperatures are preferable for soles fabrication. It is also known [6], that the length of copolymer blocks and the molecular weight of some polymers (e.g. polyurethane) can have a significant effect on the thermal, mechanical and friction properties of the material. On the basis of a planned experiment and assessing the importance according to Fischer criterion [7] it can be stated that the friction properties of a sole could be tailored by altering the surface morphology and hardness of the material.

Patent literature describes a number of compositions of rubber compounds with enhanced traction on ice and snow which comprise: 5 -norbornene at $5 \div$ $100 \mathrm{phr}[8] ; 35 \div 50 \mathrm{phr}$ hollow spherulitic microparticles of at least one aluminosilicate of $2 \div 500 \mathrm{~m} \mu$ [9]; $5 \div 50 \mathrm{phr}$ photocrosslinking liquid polymeric resin, e.g. poly(butadiene acrylate) or poly(butadiene metacrylate) [10]; $2 \div 50 \mathrm{phr}$ water soluble powder magnesium sulfate microparticles and $2 \div 50 \mathrm{phr}$ water soluble poly(vinyl alcohol) short fibers [11]; between 2 and $60 \mathrm{phr}$ microparticles of potassium, sodium, magnesium, calcium salts (chlorides, carbonates, sulphates or their mixtures) $3 \div 600 \mathrm{~m} \mu$ in size [12].

Nowadays the use of carbon black in rubber industry is restricted since it has been classified as a Group 2B carcinogenic agent, which is possibly carcinogenic 
to human beings [13] [14]. That is due mainly to its poor solubility, which extends the retention time thereby increasing the negative impact. The highest exposure is during its manufacture and hence alternate filling agents to reduce its use have been sought [15]. On the other hand, in recent years environmental protection has been gaining significance and becoming highly important for the innovation strategies of leading companies in the world. The rubber industry is no exception. The concept of environmental protection, adapted to its specificity and perceived on a wider scale, is usually associated with the maximum use of elastomers and ingredients from renewable sources in rubber products manufacturing.

For instance, a number of authors have reported improved mechanical properties, resistance to heat aging, processability, heat buildup and dynamic mechanical properties of the vulcanizates when using microcrystalline cellulose as a filler [16] [17]. Comparative studies, dealing with the influence of rice husk ash on the properties of elastomers [18], epoxidized natural rubber (NR) [19], 75:25 NR/ethylene-propylene-diene monomer blends [20] [21] as well as the impact of the most commonly used fillers: carbon black, commercial $\mathrm{SiO}_{2}$ and calcium carbonate have been published. The data refer to determination of the vulcanization characteristics, physico-chemical parameters, dispersion and degree of interaction with the rubber matrix. However, no data have been found about the influence of rice husk ash on the static and dynamic coefficient of friction of the composites on icy surfaces, both of the filler itself and of its combination with other fillers obtained from renewable sources.

In the same time it is known that the chemical modification of natural rubber latex via epoxidation yields epoxidised natural rubber (ENR) that has improved properties depending on the degree of epoxidation [22]. Epoxidation increases the polarity of natural rubber [23]. The presence of polar epoxide groups in ENR results in rubber compatible with highly polar filler like silica. Due to the strong interaction between ENR and silica in the composite acquires unique properties [24] [25].

Taking into account the above mentioned the aim of the work is to investigate the possibilities of using elastomers (epoxidized natural rubber) and ingredients from renewable sources-silica obtained by rice husks incineration and microcrystalline cellulose-as fillers, and rapeseed oil, as a process additive, to prepare compositions, intended for manufacturing soles for winter footwear having an increased coefficient of friction to icy surfaces.

\section{Experimental}

\subsection{Elastomers and Ingredients}

Epoxyprene 25 (Made in Thailand) comprising 25\% of epoxy groups; glass transition temperature $\left(T_{g}\right)$ minus $47^{\circ} \mathrm{C}, 0.97 \mathrm{~g} \cdot \mathrm{cm}^{-3}$ density and Mooney viscosity $\mathrm{ML}(1+4), 100^{\circ} \mathrm{C} 50-70$ in amount of $100 \mathrm{phr}$ was used for the investigations carried out. 
Biogenic amorphous silica obtained by rice husk incineration (SRHI) was used as filler [26]. Its characteristics were: $38 \mathrm{~m}^{2} \cdot \mathrm{g}^{-1}$ B.E.T. specific surface area; $0.49 \mathrm{~g} \cdot \mathrm{cm}^{-3}$ bilk density; $0.7 \%$ weight loss at $105^{\circ} \mathrm{C}$ (Bulgarian State Standard (BDS) ISO EN 787-2) and pH 6.5 of an aqueous solution (BDS EN ISO-787-9).

Standard silica Ultrasil 7000 GR with the following characteristics was from Evonik, Germany: $175 \mathrm{~m}^{2} \cdot \mathrm{g}^{-1}$ B.E.T. specific surface area; $0.55 \mathrm{~g} \cdot \mathrm{cm}^{-3}$ bulk density; $5.5 \%$ weight loss at $105^{\circ} \mathrm{C}$ and $\mathrm{pH} 6.5$ of an aqueous solution.

Carbon black N550 characterized by: particle size $50 \div 65 \mathrm{~nm} ; 45 \div 60 \mathrm{~m}^{2} \cdot \mathrm{g}^{-1}$ B.E.T. specific surface area; oil number $96 \div 100 \mathrm{ml} / 100 \mathrm{~g}$ and $7 \div 9 \mathrm{pH}$, at an amount of $3 \mathrm{phr}$ was used as a pigment.

Microcrystalline cellulose (Sigma-Aldrich, USA) with characteristics as follow: particle size ranging from 5 to $30 \mu \mathrm{m}, \mathrm{pH} 5$ - 7.5; water-soluble substances $\leq$ $0.24 \%$ and weight loss at $105^{\circ} \mathrm{C} \leq 5 \%$.

The compatibilizers used were:

-bis(triethoxysilylpropyl)tetrasulfide (TESPT) - silane Si $69^{\circledR}$-a bifunctional sulfur-containing organosilane from Evonik Industries. The sulfur content of TESPT was about $22.5 \mathrm{wt} . \%$; molecular weight of $532 \mathrm{~g} \cdot \mathrm{mol}^{-1}$ and $1.1 \mathrm{~g} \cdot \mathrm{cm}^{-3}$ density. The compound was used only in the silica-containing composites.

-3-thiocyanato-propyl triethoxysilane ( $\mathrm{Si}$ - 264, also manufactured by Evonik Industries) with a sulfur content of $12.5 \mathrm{wt} . \%$ and average molecular weight of $263 \mathrm{~g} \cdot \mathrm{mol}^{-1}$ was used in the compounds containing microcrystalline cellulose.

The other ingredients used for manufacturing the rubber composites (zinc oxide, stearic acid, anti-aging agents, vulcanization accelerators and activators and vulcanization agents) were standard for the rubber industry, at an equal quantity for each sample.

\subsection{Characterization}

The fillers used, silica and microcrystalline cellulose, were investigated by TEM/XEDS. The TEM observations were performed on a TEM JEOL 2100 instrument, at an accelerating voltage of $200 \mathrm{kV}$. The specimens were prepared by grinding and ultrasonic dispersing in ethanol for $6 \mathrm{~min}$. The suspensions were dripped on standard holey carbon/Cu grids. The chemical elemental composition of the fillers was determined by use of OXFORD INSTRUMENTS, X-MAX ${ }^{\mathrm{N}}$ $80 \mathrm{~T}$.

The surface compositions of the NR samples filled with silica were investigated by X-ray diffraction (XRD) and X-ray photoelectron spectroscopy (XPS).

$\mathrm{X}$-ray analysis was performed on a Bruker D8 Advance diffractometer at $\mathrm{Cu}-\mathrm{K} \alpha$ radiation, in the range of $10^{\circ}$ to $80^{\circ} 2 \theta$ degrees.

The XPS measurements were carried out on an AXIS Supra electron spectrometer (Kratos Analitycal Ltd.) using $\mathrm{AlK}_{\alpha}$ radiation with photon energy of $1486.6 \mathrm{eV}$. The energy calibration was performed by normalizing the C1s line of adsorbed adventitious hydrocarbons to $284.6 \mathrm{eV}$. The binding energies (BE) were determined with an accuracy of $\pm 0.1 \mathrm{eV}$. The chemical composition of the 
samples was determined monitoring the areas and binding energies of $\mathrm{C} 1 \mathrm{~s}, \mathrm{O} 1 \mathrm{~s}$ and Si2p photoelectron peaks. Using the commercial data-processing software of Kratos Analytical Ltd. the concentrations of the different chemical elements in atomic percentages were calculated by normalizing the areas of the photoelectron peaks to their relative sensitivity factors.

\subsection{Compositions of the Rubber Compounds Used}

The elastomers and ingredients used are described in the Experimental Part above (2.1. Elastomers and Ingredients). The differences in the formulations of the compounds used to manufacture soles for sporting winter boots are shown in Table 1.

\subsection{Preparation and Vulcanization of the Rubber Compounds}

The compounds were prepared on an open two-roll laboratory mill (rolls Length/Diameter $320 \times 160 \mathrm{~mm}$, friction 1.17 and $25 \mathrm{~min}^{-1}$ speed of the slower rotating roll). The rubber compounds were vulcanized in the form of $400 \times 400$ $\mathrm{mm}$ plates on an electrically hydraulic vulcanization press at $150^{\circ} \mathrm{C}$, at $10 \mathrm{MPa}$ and for a time determined by the vulcanization isotherms of the compounds taken on a MDR 2000, Alpha Technology vulcameter.

\subsection{Characterization of the Rubber Compounds and Vulcanizates Based on Them}

The compounds and vulcanizates were characterized as follows:

- Vulcanization characteristics-determined according to ISO 3417: 2002;

- Physico-mechanical properties (Modules at $100 \%$ and 300\% elongation, tensile strength, relative elongation, residual elongation) - according to ISO 37: 2002 and EN 12 803;

- Shore A hardness according to ISO 7619:2001

- Dynamic characteristics-the tangent of the mechanical loss angle $(\tan \delta)$ at a frequency of $5 \mathrm{~Hz}, 64 \mu \mathrm{m}$ deformation, in the temperature range of minus 80 to $+80^{\circ} \mathrm{C}$, in particular at minus $10^{\circ} \mathrm{C}$, minus $4^{\circ} \mathrm{C}$, and minus $1^{\circ} \mathrm{C}$, at a heating rate of $3^{\circ} \mathrm{C} \cdot \mathrm{min}^{-1}$. The size of the samples tested was as follows: 10 $\mathrm{mm}$ width, $25 \mathrm{~mm}$ length and $2 \mathrm{~mm}$ thickness. A dynamic mechanical thermal analyzer, manufactured by Rheometric Scientific was used.

- Wear resistance: according to EN 12 770;

Table 1. Compositions of the rubber compounds (phr).

\begin{tabular}{ccccc}
\hline Component & ENR 0 & EMCC 1 & EMCC 2 & EMCC 3 \\
\hline Microcrystalline cellulose & - & 60 & 30 & 30 \\
Silica from rice husk & - & - & 30 & \\
Silica Ultrasil 7000 GR & - & - & - & 30 \\
Si-264 & - & 6 & 3 & 3 \\
Si 69 & - & - & 3 & 3 \\
\hline
\end{tabular}


- Bending resistance: according to BDS 5658-72;

- Tribological characteristics: the static and dynamic coefficient of friction were determined using a laboratory apparatus and methods

A functional scheme of the device used is presented in Figure 1. The tribological system consists of a tested sample (1) and contrabody (2). The sample of a certain size was fixed into a holder (3) (sledge) which was attached to the dynamometer (6) and a micrometric screw (5) by means of a non-elastic thread. The lower surface of the holder (3) was set at $2 \mathrm{~mm}$ over the contact surface between the sample (1) and contrabody (2). Measurements of the static friction force $\left(\mathrm{T}_{\mathrm{o}}\right)$ using the shown device (Figure 1) were carried out in the following order: the sample (1) was fixed into the holder (3) and a given load P was determined with the help of the loads (4). The scale of the dynamometer (6) was reset and a tangential force $\mathrm{F}$ was set over the sample holder (1) smoothly through the non-elastic thread by a slow movement of the micrometer screw $\left(10 \mu \mathrm{m} \cdot \mathrm{s}^{-1}\right)$. The value of the force $\mathrm{F}$ was measured on the dynamometer scale (6) tilled in N. The maximum value of the force $F_{o}$ was indicated by the dynamometer scale via a recoded movement of its pointer, then force $\mathrm{F}$ was decreased. The rate of static friction force $T_{0}$ was equal to the maximum deviation of the dynamometer pointer, the dynamic frictional force $\mathrm{T}$ was equal to the dynamometer reading when moving the sample (1). Figure 2 presents a photograph of the laboratory device for measuring the static and dynamic friction force placed into a cryogenic chamber for the purpose of determining the coefficient of friction at low temperatures.

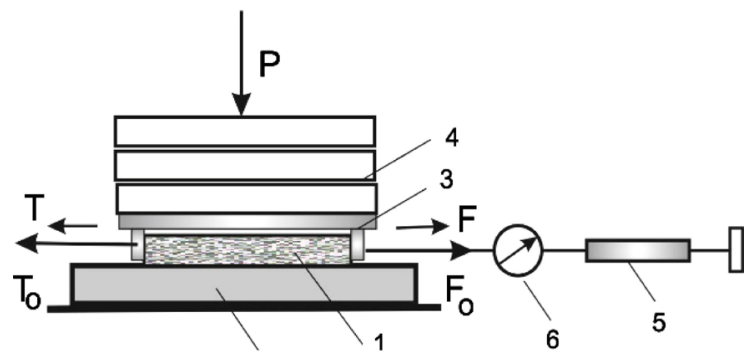

Figure 1. Functional scheme of a laboratory device for studying static and kinetic friction at a slow sliding rate: 1-sample; 2-contrabody; 3-sample holder; 4-loads; 5-micrometer screw; 6-dynamometer.

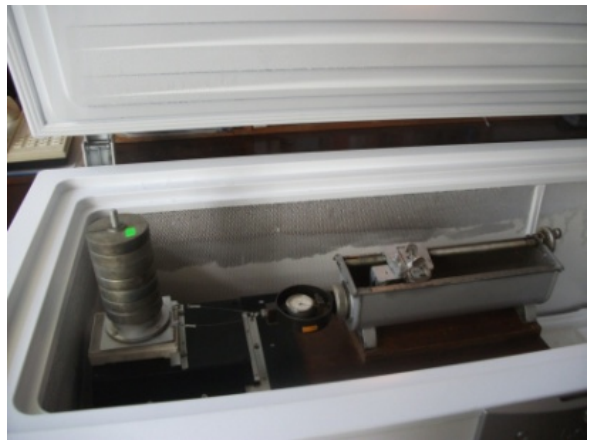

Figure 2. Tribological experimental design. 
A small parallelepiped ice block was used as a contrabody. The icy surface was evened via treatment with liquid sandpaper STRUERSP180. The samples tested were evacuated into the camera for $30 \mathrm{~min}$ prior to the measurements. For each experiment the measurements were performed trice and the average value was taken into account. The standard deviations, SD for each measurement was within the accuracy of the method \pm 0.01 . The dynamic friction coefficient $\mu$ was calculated by the formula (Equation (1)):

$$
\mu=T / P
$$

The measurements were carried out at temperatures below zero: $-10^{\circ} \mathrm{C}$ (corresponding to the so called "dry" ice); $-4^{\circ} \mathrm{C}$ (corresponding to the so called "wet" ice) and $-1^{\circ} \mathrm{C}$ (corresponding to so called "melting" ice, i.e. ice covered by a layer of water).

\section{Results and Discussion}

\subsection{Characteristics of the Fillers and the Samples Containing Them}

A comparison of EDX spectroscopy maps shows that the chemical elemental composition of the three fillers is quite different. The data are presented as Figures 1(a)-(c) in Supporting Information. Noteworthy is also that the elemental composition of standard silica is quite different from that of silica obtained by rice husk incineration. The atomic percentage of the elements is also quite different (Table 2).

The data in Table 2 show that standard silica contains 5 elements with predominant amounts of oxygen, aluminum, silicon and no carbon. However, silica from rice husk contains 11 elements, with predominant amounts of silicon, oxygen, potassium and calcium, which in turn are standard silica does not contain. These differences in the fillers elemental composition are undoubtedly due

Table 2. Compositions of the fillers according to EDX data, at. \%.

\begin{tabular}{cccc}
\hline Chemical element & Ultrasil 7000 GR & SRHI & MCC \\
\hline $\mathrm{O}$ & 47.94 & 49.58 & 5.68 \\
$\mathrm{Na}$ & 0.34 & 0.17 & 0.98 \\
$\mathrm{Al}$ & 38.77 & 2.04 & - \\
$\mathrm{Si}$ & 12.79 & 29.02 & 0.51 \\
$\mathrm{Ca}$ & 0.16 & 7.42 & - \\
$\mathrm{Mg}$ & - & 0.31 & - \\
$\mathrm{P}$ & - & 0.23 & - \\
$\mathrm{K}$ & - & 9.31 & - \\
$\mathrm{Mn}$ & - & 1.15 & - \\
$\mathrm{Fe}$ & - & 0.62 & - \\
$\mathrm{C}$ & - & - & 92.71 \\
$\mathrm{Cl}$ & - & - & 0.12 \\
\hline
\end{tabular}


to the fact that in the first case we have a synthetic product and in the other a natural one. There is a large difference in the size and shape of the elementary particles (Figure 3): in the first case, they are approximately spherical in shape and size about $20 \mathrm{~nm}$ (Figure 3(a)). In the second case those are of irregular shape and size in the range of $200-500 \mathrm{~nm}$ (Figure 3(b)).

The XRD data presented in Figure 4(a) show a significant difference in the degree of crystallinity of the two fillers, containing $\mathrm{SiO}_{2}$. The peak at about $22^{\circ}$ $2 \Theta$ observed for the SRHI sample is indicative of the biogenic $\mathrm{SiO}_{2}$ produced by the incineration of rice husk. It contains predominantly a cristobalite phase at an initial stage of crystallization [27] [28]. The pattern of the diffractogram for commercial product is typical for amorphous precipitated silica. The shift of the peak to higher angles compared with that of SRHI is related to differences in the parameters (111) of the crystal lattice. This is due to the technology of obtaining both products. SRHI is obtained at a much higher temperature $\left(800^{\circ} \mathrm{C}\right)$ compared with the commercial product.

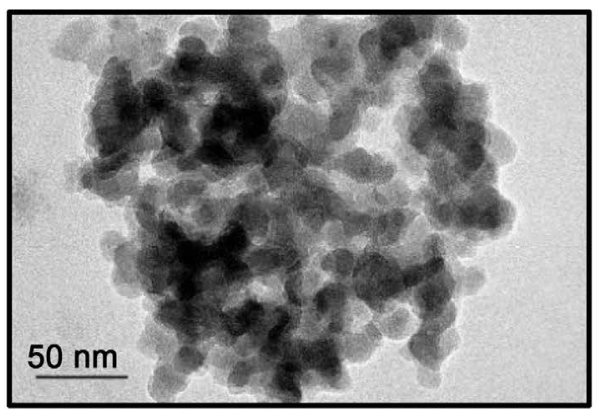

(a)

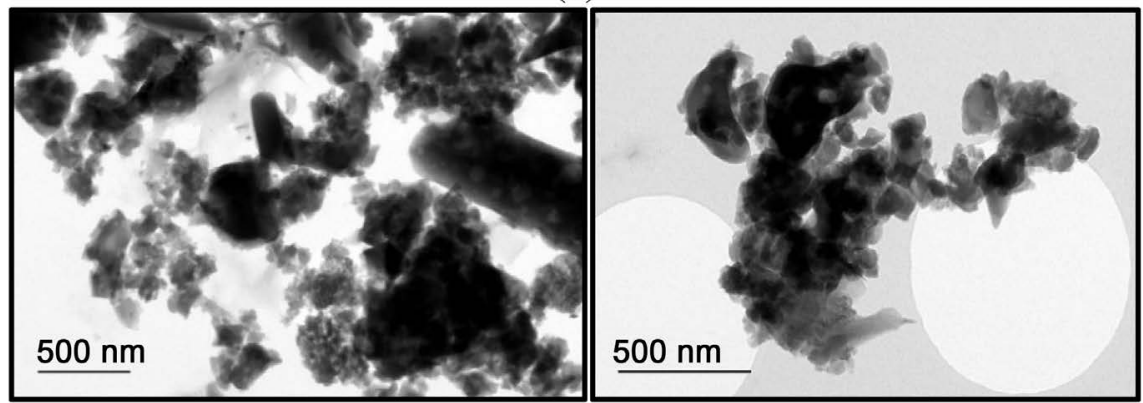

(b)

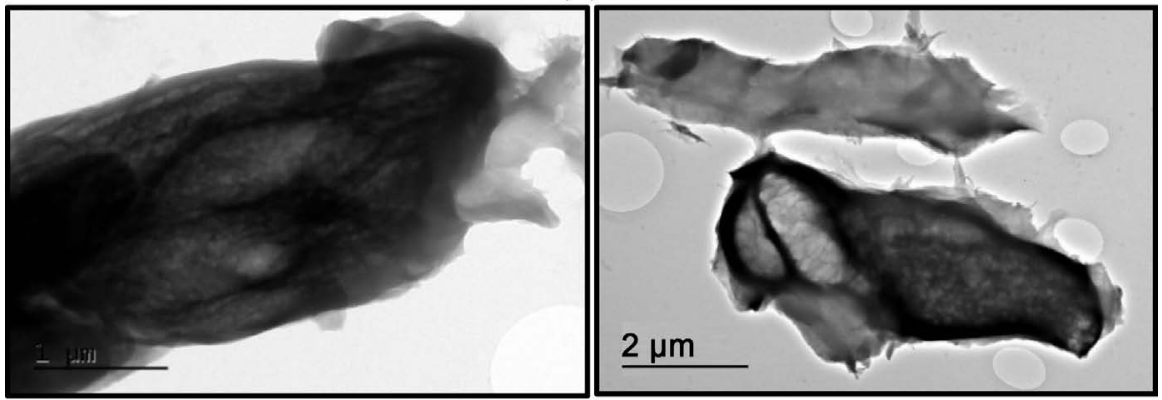

(c)

Figure 3. TEM micrographs of: (a) Ultrasil 7000 GR; (b) SRHI; (c) Microcrystalline cellulose experimental. 
The XRD patterns for elastomers EMCC 2 and EMCC 3 (Figure 4(b)) reflect the difference in the crystallinity of the two types of silicon dioxide.

The surface composition of the samples was investigated by XPS, Figure 5. As seen, the peaks for the sample containing commercial $\mathrm{SiO}_{2}$ associated with $\mathrm{C} 1 \mathrm{~s}$, O1s and Si2p are considerably larger compared with those for sample EMCC-2 filled with biogenic $\mathrm{SiO}_{2}$. That is due to the difference in the granulometry and crystallinity degree of the two fillers, as it has been discussed above.
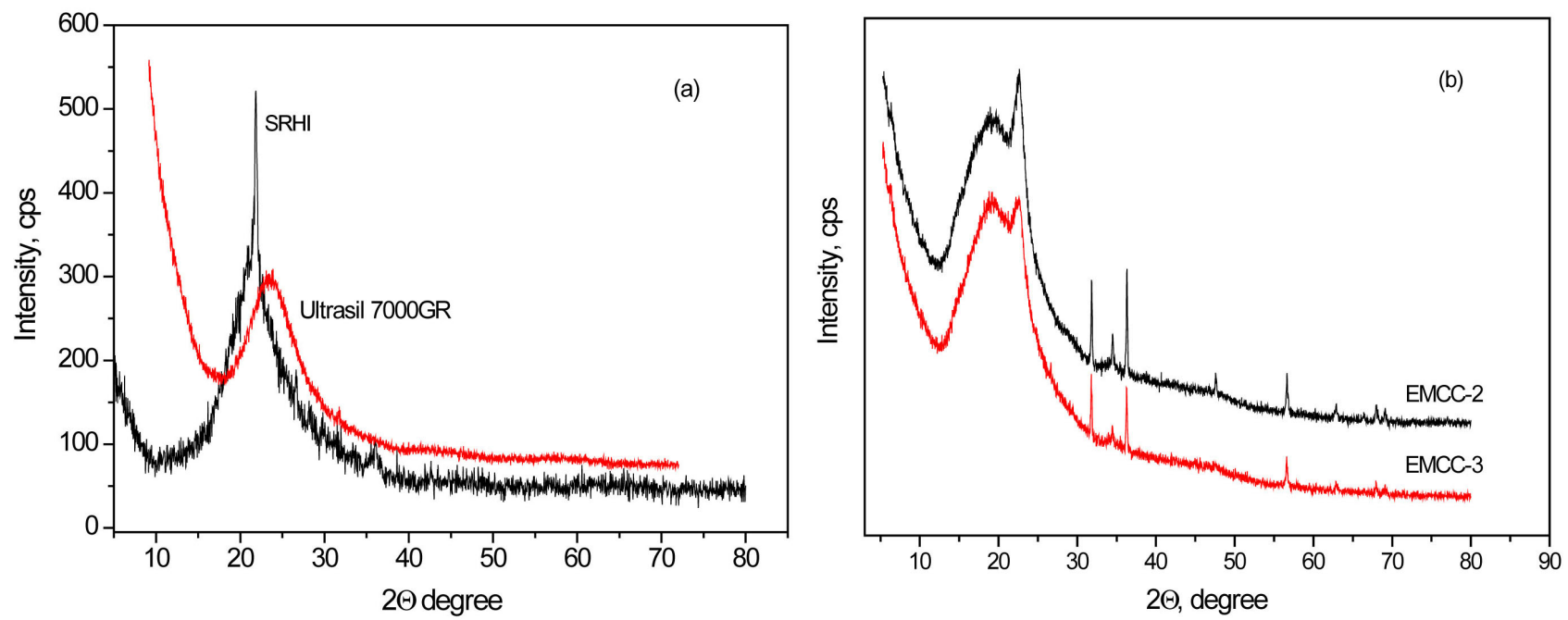

Figure 4. X-ray diffraction of: (a) Ultrasil 7000 GR and SRHI; (b) the samples, containing the two fillers.
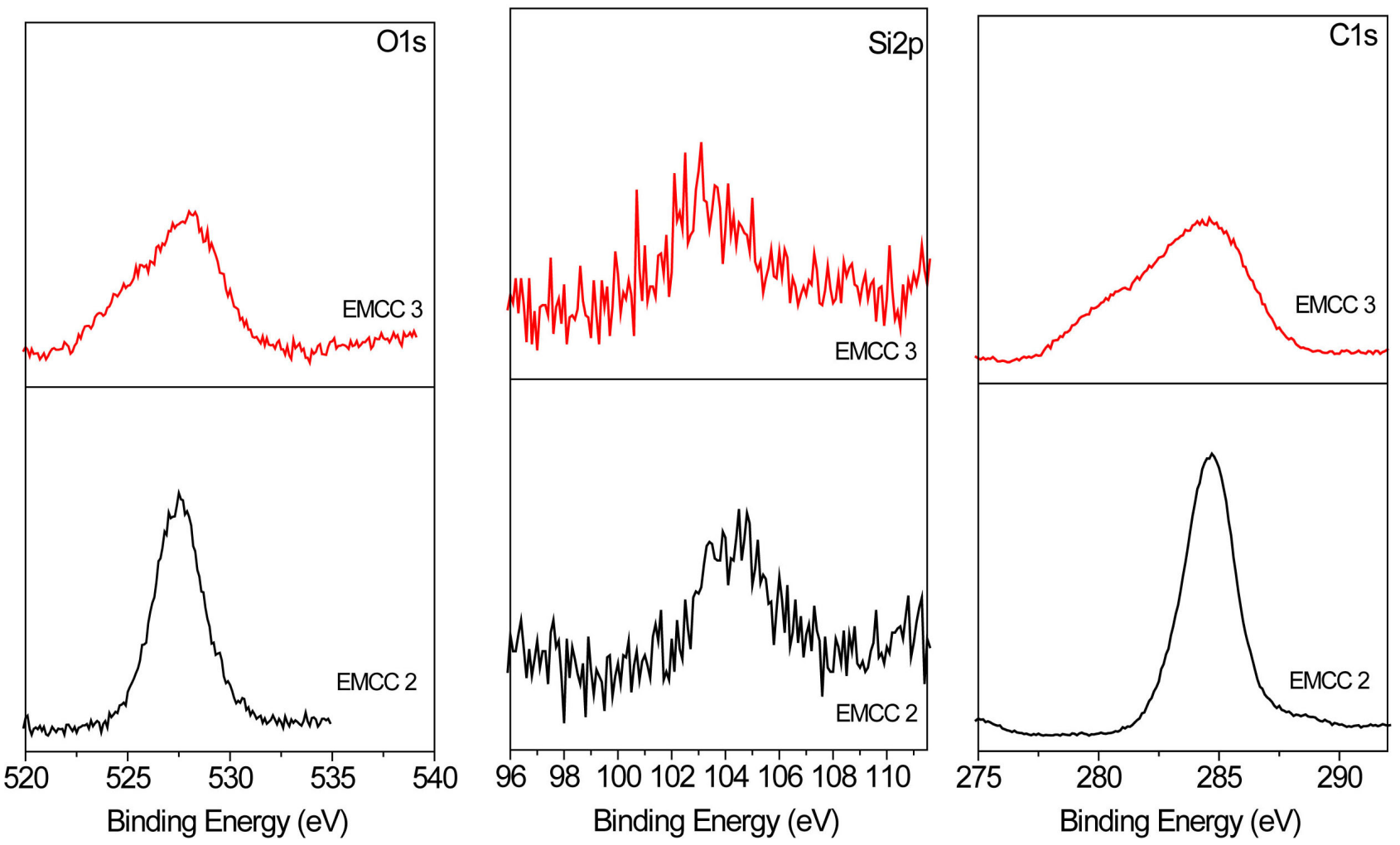

Figure 5. XPS analysis of samples EMCC 2 and EMCC 3. 


\subsection{Vulcanization Characteristics}

The vulcanization characteristics of the investigated compounds are summarized in Table 3, where minimum torque ML correlates with the effective viscosity of the mixture and $\mathrm{MH}$ is maximum torque correlating with the hardness of the compounds. The difference $\Delta \mathrm{M}=\mathrm{MH}-\mathrm{ML}$ correlates with the density of the vulcanization network. Ts1 is connected with the scorch till one torque unit rise above the minimum and correlates with the resistance to premature vulcanization. Ts 2 is the time till the beginning of the vulcanization process (increase of the torque by 2 units) and correlates with the resistance to premature vulcanization. $\mathrm{T}_{50}$ expresses the time needed to run $50 \%$ of the vulcanization process and $\mathrm{T}_{90}$-the time to run $90 \%$ of the vulcanization process (optimum vulcanization time).

As seen from the results summarized in Table 3, the vulcanization characteristics of the compounds tested vary considerably depending on the chemical nature of the filler used. For comparison, the values for the composition which does not contain any filler, are the lowest. Amongst the filled formulations, the lowest values for all parameters are for those containing only microcrystalline cellulose. Silica introduction leads to a significant increase in all values of the vulcanization characteristics, the effect being more pronounced for the composition containing standard silica compared to that containing the same amount of SRHI. The observed effects can be explained by the fact that microcrystalline cellulose is softer, with a plasticizing effect and obviously a filler less active than silica. The surface of the latter adsorbs the accelerators, thus retarding the vulcanization process.

\subsection{Physicomechanical Characteristics}

The physicochemical characteristics of vulcanizates containing elastomers and ingredients from renewable resources are summarized in Table 4.

The analysis of the results in Table 4 shows that a decrease of the fillers particles size and an increase in their specific surface area, improves their reinforcing potency as well as all physicomechanical characteristics, as evidenced by

Table 3. Vulcanization characteristics of rubber compounds containing elastomers and ingredients from renewable resources (ENR 0 is the control virgin sample).

\begin{tabular}{ccccc}
\hline Characteristic & ENR0 & EMCC1 & EMCC2 & EMCC3 \\
\hline ML, dNm & 0.00 & 0.03 & 0.43 & 0.84 \\
MH, dNm & 4.53 & 9.61 & 20.26 & 25.71 \\
$\Delta \mathrm{M}=\mathrm{MH}-\mathrm{ML}$ & 4.53 & 9.58 & 19.83 & 24.87 \\
Ts1, min:sec & $4: 19$ & $3: 57$ & $4: 29$ & $5: 11$ \\
$\mathrm{Ts}_{2}, \min : \mathrm{sec}$ & $4: 34$ & $4: 10$ & $4: 51$ & $5: 31$ \\
$\mathrm{~T}_{50}, \min : \mathrm{sec}$ & $4: 39$ & $4: 50$ & $5: 46$ & $7: 21$ \\
$\mathrm{~T}_{90}, \min : \mathrm{sec}$ & $5: 35$ & $7: 32$ & $9: 38$ & $12: 08$ \\
\hline
\end{tabular}


Table 4. Physicomechanical properties of the vulcanizates.

\begin{tabular}{|c|c|c|c|c|c|}
\hline Parameter & ENR 0 & EMCC 1 & EMCC 2 & EMCC 3 & $\begin{array}{l}\text { Recommended } \\
\text { values }\end{array}$ \\
\hline Modulus at $100 \%$ of elongation, $\mathrm{M}_{100,} \mathrm{MPa}$ & 0.3 & 0.7 & 1.4 & 2.1 & - \\
\hline Modulus at $300 \%$ of elongation, $\mathrm{M}_{300}, \mathrm{MPa}$ & 0.7 & 2.1 & 4.8 & 5.7 & - \\
\hline Tensile strength, $\sigma, \mathrm{MPa}$ & 9.0 & 3.5 & 10.7 & 12.0 & Min 8 [29] \\
\hline Relative elongation, $\varepsilon_{1}, \%$ & 750 & 450 & 570 & 590 & Min 300 [29] \\
\hline Residual elongation, $\varepsilon_{2}, \%$ & 10 & 15 & 30 & 30 & - \\
\hline Shore A Hardness, relative units & 45 & 60 & 70 & 71 & $60-88[29]$ \\
\hline Abrasion resistance, $\mathrm{mm}^{3}$ & 410 & 400 & 195 & 175 & $\operatorname{Max} 150[29]$ \\
\hline Density,g. $\mathrm{cm}^{-3}$ & 0.95 & 1.05 & 1.14 & 1.16 & Max $1.25[29][30]$ \\
\hline Fatigue failure resistance, cycles & $>60,000$ & $>60,000$ & $>60,000$ & $>60,000$ & $\operatorname{Min} 40,000[30]$ \\
\hline Tear strength, $\mathrm{N} \cdot \mathrm{mm}^{-1}$ & 2.0 & 2.5 & 8.1 & 8.9 & $\operatorname{Min} 8$ [29] \\
\hline
\end{tabular}

TEM studies, described further on. The low reinforcement potency of microcrystalline cellulose, in addition to its low specific surface area and large particle size [31] [32], is also due to its hydrophilic surface, which has poor compatibility with the hydrophobic rubber matrix. It is obvious that additional surface modification of microcrystalline cellulose is necessary to make it hydrophobic. That will improve its compatibility with the matrix of epoxidized natural rubber and the physico-mechanical characteristics of the vulcanizates that contain it, including abrasion resistance, respectively. It may also be seen from the table that the indices of composites, containing standard silica are the highest. The difference between the indices of composites containing standard silica and SRHI is obvious. It is due to the differences in the fillers characteristics, especially their size and specific surface area. On the other hand, the results obtained indicate the strong rubber-filler interaction in ENR/silica compounds which derived from the coupling of ENR and silica as well as from the enhanced interaction with the coupling agent used. That synergistic effect results from the hybrid reinforcement of ENR with silica and a silane system. The mechanism for the hybrid interactions consist of combination of interaction and coupling between ENR and silica. The interaction of ENR and silica comes from the hydrogen bonding between the silanol groups of silica with the epoxide group in ENR. The stronger interactions between ENR and silica derived from the silica bonding with the ring opening of ENR; as well as from silica coupling with ENR through silane coupling bonding [33].

\subsection{Bending Resistance}

All composites tested were subjected to experiments to determine their "fatigue failure resistance" index as described in [30]. All composites withstand over 60,000 cycles of bending to $180^{\circ}$ without any cracking. According to the standard, samples must withstand at least 40,000 cycles without cracks, it is obvious that they meet the requirements. 


\subsection{Predicting the Ice Grip Taking into Account DMTA Data}

Dynamic mechanical thermal analysis (DMTA) allows to define the complex dynamic modulus $\mathrm{E}^{\star}$, the storage modulus $\mathrm{E}^{\prime}$ and the losses modulus $\mathrm{E}^{\prime \prime}$ of a rubber material by the reaction of the material against the impact of an oscillating force causing a sinusoidal load. The relationship between them can be represented by the equation $\mathrm{E}^{*}=\mathrm{E}^{\prime}+\mathrm{iE}$, i.e. the ability of the composite to store energy (the storage modulus expresses the elastic component of the complex dynamic modulus) and its ability to lose energy (the loss modulus expresses the plastic component of the complex dynamic modulus) [34]. Their ratio $\operatorname{tg} \delta=$ E"/E', the so called tangent of mechanical loss angle, is of particular importance. Its importance is due to a definitely established fact [35] [36], that the tangent of mechanical loss angle of the rubber material from which the sample is made at low temperatures correlates well with its ice grip (the higher the tangent, the higher the grip).

Figure 6 summarizes the data from the tangent of mechanical loss angle of the investigated rubber composites at temperatures below zero: $-10^{\circ} \mathrm{C},-4^{\circ} \mathrm{C}$ and $-1^{\circ} \mathrm{C}$, correlating with the grip to "dry" ice, "wet" ice and "melting" ice (ice covered by a layer of water), respectively.

As the results presented show, the composites containing only microcrystalline cellulose as a filler are outstanding with the highest tangent of mechanical losses angle at all the studied temperatures, with predicted highest adhesion to icy surfaces, respectively. However, it should be kept in mind that those composites have the poorest physico-mechanical performance. Of the composites containing silica, those with SHRI have higher values of the tangent of mechanical losses angle. The composites with standard silica have the lowest values. A number of authors [3] [4] point out that to ensure a good grip of the sole with icy surfaces, the material from which it is made should be soft and retain softness even at low temperatures. As seen from the physico-mechanical characteristics in Table 3, in particular the Shore A hardness, the composites containing

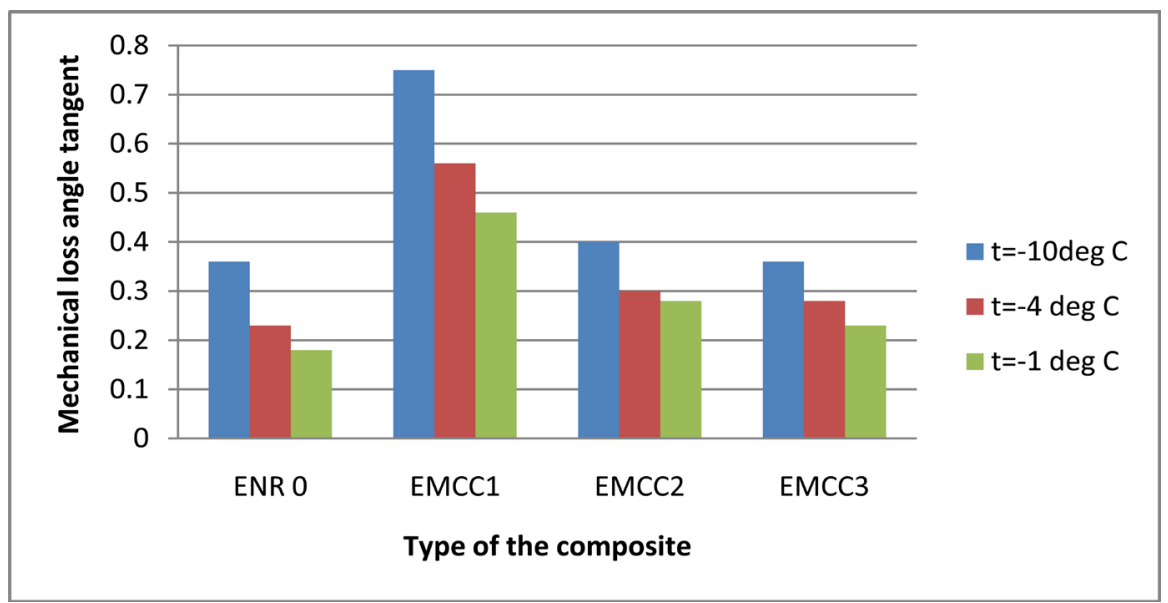

Figure 6. Tangent of mechanical loss angle of the rubber composites studied at different temperatures below zero: $-10^{\circ} \mathrm{C} ;-4^{\circ} \mathrm{C}$ and $-1^{\circ} \mathrm{C}$. 
microcrystalline cellulose have the lowest Shore A hardness value $(60 \mu \mathrm{m})$, while the composites containing SRHI and standard silica have significantly higher hardness values (70 and 71 equivalents, respectively). Shore A hardness is directly related to traction with icy surfaces-the lower the hardness, the higher the traction is, and vice versa. On the other hand, the chemical nature and structure of the filler determine its effect on the material hardness.

It is obvious that the differences in the structure, granulometry and crystallinity of the two types of silicon dioxide influences the tangent of mechanical loss angle. The predominant cristobalite phase in SRHI (Figure 4(a)) leads to a tangent value for this composite higher than that for the sample, containing commercial amorphous silica.

\subsection{Tribological Measurements}

The coefficients of kinetic friction of the composites at different temperatures are shown on Figure 7.

As seen from the results obtained, the complex estimation (physico-mechanical characteristics and kinetic coefficient of friction to various icy surfaces) reveals that the samples containing microcrystalline cellulose and SRHI possess the best parameters (EMCC-2).

The samples containing only microcrystalline cellulose (EMCC-1) have the highest values of the friction coefficients but their physico-mechanical properties are quite poor. Samples containing microcrystalline cellulose and standard silica (EMCC-3) have values of the physico-mechanical parameters higher than those of composites with biogenic silica but lower friction coefficients to icy surfaces. The differences observed again could be explained by the different structure of the two silica fillers.

The following classification of the coefficients of kinetic friction and the class of adhesion (to ice)/slip is given in the specialized literature [4] [37] (Table 5):

The above classification confirms that composites EMCC-1 and EMCC-2 with

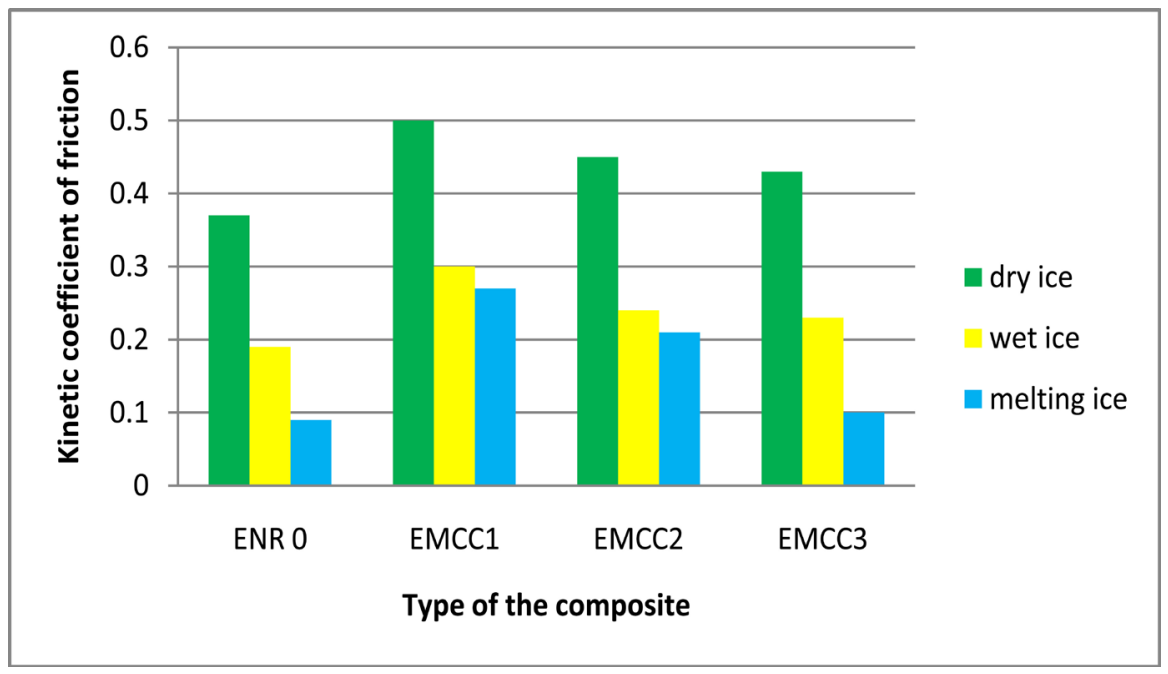

Figure 7. Coefficients of kinetic friction. 
Table 5. Classification of the adhesion class depending on the kinetic coefficient of friction.

\begin{tabular}{cc}
\hline Kinetic coefficient of friction & Degree of slip resistance \\
\hline$>0.30$ & highly stable \\
$0.20-0.29$ & stable \\
$0.15-0.19$ & unstable \\
$0.05-0.14$ & slipping \\
$<0.05$ & highly slipping \\
\hline
\end{tabular}

respect to slip resistance fall into the category "highly stable" and "stable", whereas composite EMCC-3 in one of the categories falls into the "slipping" class with a coefficient value of 0.1 . The correlation between the tangent of mechanical loss angle and the kinetic coefficient of friction with respect to the adhesion to icy surfaces is also confirmed. Since the tested composites differ only in the nature of the filler used (microcrystalline cellulose, standard silica and SRHI), it is evident that the observed effects can be explained by the significant differences in the particle size, composition, structure and properties of the fillers used. The results obtained implementing STEM-EDX, XRD and XPS methods reveal best the state of art.

It is obvious, however, that the higher hardness of the composites has a negative effect on their adhesion to icy surfaces, as other authors have established [3] [7], hence the softer composites containing silica from rice husk have higher values of the friction coefficient and are more suitable for soles making as they retain their acceptable values of the mechanical parameters.

The case of microcrystalline cellulose (Figure 4(c)) is different. As seen, carbon is predominant (Table 2), but the problem in the case is in the extremely large particle size (5 - $7 \mu \mathrm{m})$, what minimizes the reinforcing effect. The composites are much softer (since the filler itself is much softer than silica). Microcrystalline cellulose has a Young's modulus of $21-29 \mathrm{GPa}$ [38], while that of silica is $88.7 \mathrm{GPa}$ [39], i.e. as a material the former tends to deformations at considerably lower stresses with very high adhesion to icy surfaces, but with quite low physico-mechanical characteristics (Table 3 ). That is likely to cause problems with the performance characteristics of the final product. Therefore, having made a complex assessment we favor the composites containing microcrystalline cellulose and silica produced by rice husk incineration (EMCC-2), which is a compromise option for manufacturing soles with acceptable physico-mechanical characteristics, corresponding to the required values (Table 4) and acceptable values of the friction coefficient to icy surfaces (respectively $0.45 ; 0.24$ and 0.21 at temperatures $-10^{\circ} \mathrm{C},-4^{\circ} \mathrm{Cand}-1^{\circ} \mathrm{C}$ ), thereby they could be classified in the categories "very stable" and "stable". The soles produced are shown in Figure 8.

\section{Conclusions}

Various variants of rubber compounds and vulcanizates based on them have 


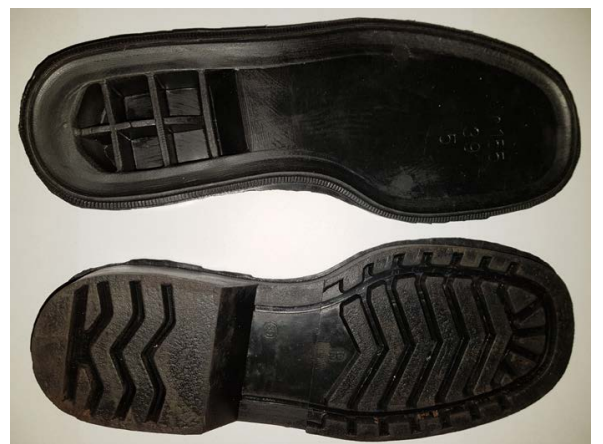

Figure 8. Soles produced using a composite containing $89 \%$ of products from renewable resources.

been developed for the production of soles with increased adhesion to icy surfaces. Those contain elastomers and ingredients from renewable natural sourcesepoxidized natural rubber, microcrystalline cellulose, silica produced by rice husks incineration, rapeseed oil. The compounds and vulcanizates were classified with respect to the performance standards laid down for footwear soles based on elastomers and it was demonstrated that the materials meet those standards. The adhesion of the materials as well as tribological tests based on the coefficient of friction was evaluated by dynamic mechanical thermal analysis, at different temperatures.

The complex evaluation of the composites developed revealed those containing microcrystalline cellulose and biogenic amorphous silica at a 1:1 ratio to be the most suitable for making footwear soles. The reason for the higher coefficient of friction of the composite, containing SRHI compared to those of composites filled with standard silica is due to different crystallinity-a predominant cristobalite phase in the first case and a completely amorphous phase in the second.

The amount of elastomers and ingredients from renewable sources (elastomers, fillers, process additives) predominate in the developed composites reaching $89 \%$. That indicates good capacity of those products to improve the friction coefficients to icy surfaces.

\section{Acknowledgements}

The implementation of this study was funded by the Operational Program 2014BG16RFOP002-Innovation and Competitiveness, Procedure:

BG16RFOP002-1.002-Support for the development of innovations by start-ups, Grant Agreement BG16RFOP002-1.002-0028-C01 Eco-footwear soles on elastomeric basis with improved ice and snow grip.

\section{References}

[1] Lurid, J. (1984) Accidental Falls at Work, in the Home and during Leisure Activities. Journal of Occupational Accidents, 6, 181-193.

[2] Honkanen, R. (1982) The Role of Slippery Weather in Accidental Falls. Journal of Occupational Accidents, 4, 257-262. https://doi.org/10.1016/0376-6349(82)90033-5 
[3] Derler, S., Kausch, F. and Huber, R. (2008) Analysis of Factors Influencing the Friction Coefficients of sHoe Sole Materials. Safety Science, 46, 822-832. https://doi.org/10.1016/j.ssci.2007.01.010

[4] Groonqvist, R. and Hirvonen, M. (1995) Slipperiness of Footwear and Mechanisms of Walking Friction on Icy Surfaces. International Journal of Industrial Ergonomics, 16, 191-200. https://doi.org/10.1016/0169-8141(94)00095-K

[5] Gao, C., Abeysekera, J., Hirvonen, M. and Aschan, C. (2003) The Effect of Footwear Sole Abrasion on the Coefficient of Friction on Melting and Hard Ice. International Journal of Industrial Ergonomics, 31, 323-330. https://doi.org/10.1016/S0169-8141(02)00234-2

[6] Takahashi, T., Hayashi, N. and Hayashi, S. (1996) Structure and Properties of Shapememory Polyurethane Block Copolymers. Journal of Applied Polymer Science, 60, 1061-1069.

https://doi.org/10.1002/(SICI)1097-4628(19960516)60:7<1061::AID-APP18>3.0.CO $\underline{; 2-3}$

[7] McLachlan, G. (2004) Discriminant Analysis and Statistical Pattern Recognition. Wiley Interscience.

[8] US Patent $4427831 / 1984$.

[9] Michelin's Eurasian Patent 201290524.

[10] World Patent WO 2012/146611A1 by Michelin.

[11] World Patent WO 2011/073188 A1 by Michelin.

[12] World Patent WO 2014/067828 by Michelin.

[13] Baan, R. (2007) Carcinogenic Hazards from Inhaled Carbon Black, Titanium Dioxide, and Talc Not Containing Asbestos or Asbestiform Fibers: Recent Evaluations by an IARC Monographs, Working Group. Inhalation Toxicology, 19, 213-228. https://doi.org/10.1080/08958370701497903

[14] Sorahan, T. and Harrington, J. (2007) A "Lugged" Analysis of Lung Cancer Risks in UK Carbon Black Production Workers, 1951-2004. American Journal of Industrial Medicine, 50, 555-564. https://doi.org/10.1002/ajim.20481

[15] Barlow, P., Clouter-Baker, A., Donaldson, K., MacCallum, J. and Stone, V. (2005) Carbon Black Nanoparticles Induce Type II Epithelial Cells to Release Chemotaxins for Alveolar Macrophages. Particle and Fibre Toxicology, 2, 11-25. https://doi.org/10.1186/1743-8977-2-11

[16] Xu, S.H., Gu, J., Luo, Y.F. and Jia, D.M. (2012) Effects of Partial Replacement of Silica with Surface Modified Nanocrystalline Cellulose on Properties of Natural Rubber Nanocomposites. eXPRESS Polymer Letters, 6, 14-25. https://doi.org/10.3144/expresspolymlett.2012.3

[17] Mansor, M. (2016) Properties Evaluation of Micro-Crystalline Cellulose and Starch as Biofiller in Rubber Compounding. Advanced Materials Research, 1133, 593-597.

[18] Arayapranee, W., Na-Ranong, N. and Rempel, G. (2005) Application of Rice Husk Ash as Fillers in the Natural Rubber Industry. Journal of Applied Polymer Science, 98, 34-41. https://doi.org/10.1002/app.21004

[19] Pongdong, W., Nakason, C., Kummerlöwe, C. and Vennemann, N. (2015) Influence of Filler from a Renewable Resource and Silane Coupling Agent on the Properties of Epoxidized Natural Rubber Vulcanizates. Journal of Chemistry, 2015, Article ID: 796459. https://doi.org/10.1155/2015/796459

[20] Arayapranee, W. and Rempel, G. (2008) A Comparative Study of the Cure Characteristics, Processability, Mechanical Properties, Ageing, and Morphology of Rice 
Husk Ash, Silica and Carbon Black Filled 75:25 NR/EPDM Blends. Journal of Applied Polymer Science, 109, 932-941. https://doi.org/10.1002/app.28111

[21] Arayapranee, W. and Rempel, G. (2008) A Comparison of the Properties of Rice Husk Ash, Silica, and Calcium Carbonate Filled 75:25 NR/EPDM Blends. Journal of Applied Polymer Science, 110, 1165-1174. https://doi.org/10.1002/app.28725

[22] Baker, C., Gelling, I. and Samsuri, A. (1986) Epoxidised Natural Rubber. Journal of Natural Rubber Research, 1, 135-144.

[23] Gelling, I. (1991) Epoxidised Natural Rubber. Journal of Natural Rubber Research, 6, 184-205.

[24] Baker, C., Gelling, I. and Palmer, J. (1985) Epoxidised Natural Rubber in Passenger Car Tire Treads. Proceedings of International Rubber Conference 1985 Kuala Lumpur, 336-352.

[25] Sarkawi, S. and Mt Saad, C. (2011) Reinforcement of Epoxidised Natural Rubber by Precipitated Silica Nanofiller: Studies on Cure Characteristics and Rubber-Filler Interaction. Journal of Industrial Technology, 20, 103-121.

[26] Dishovsky, N., Malinova, P. and Uzunov, I. (2017) Biogenic Amorphous Silica as Filler for Elastomers. Journal of Renewable Materials. https://doi.org/10.7569/JRM.2017.634171

[27] Lanning, F.C. (1963) Plant Constituents, Silicon in Rice. Journal of Agricultural and Food Chemistry, 11, 435-437. https://doi.org/10.1021/jf60129a024

[28] Hanna, S., Farag, L. and Mansour, N. (1984) Pyrolysis and Combustion of Treated and Untreated Rice Hulls. Thermochimica Acta, 81, 77-86. https://doi.org/10.1016/0040-6031(84)85112-6

[29] Yuvaraj, P., Raghava Rao, J., Nishad Fathima, N., Natchimuthu, N. and Mohan, R. (2017) Complete Replacement of Carbon Black Filler in Rubber Sole with $\mathrm{CaO}$ Embedded Activated Carbon Derived from Tannery Solid Waste. Journal of Cleaner Production, 170, 446-450. https://doi.org/10.1016/j.jclepro.2017.09.188

[30] Bulgarian State Standard N 5658-72.

[31] Medalia, A. (1978) Effect of Carbon Black on Dynamic Properties of Rubber Vulcanizates. Rubber Chemistry and Technology, 51, 437-523. https://doi.org/10.5254/1.3535748

[32] Poh, B., Ismail, H. and Tan, K. (2002) Effect of Filler Loading on Tensile and Tear Properties of SMR L/ENR 25 and SMR L/SBR Blends Cured via a Semi-Efficient Vulcanization System. Polymer Testing, 21, 801-806. https://doi.org/10.1016/S0142-9418(02)00014-4

[33] Sarkawi, S., Aziz, A., Rahim, R., Ghani, R. and Kamaruddin, A. (2016) Properties of Epoxidized Natural Rubber Tread Compound: The Hybrid Reinforcing Effect of Silica and Silane System. Polymers \& Polymer Composites, 24, 775-781.

[34] Matador, S. (2007) Test Methods of Rubber Materials and Products. VERT, 111-113.

[35] Martens, J., Terrill, E., Lewis, J., Pazur, R. and Hoffman, R. (2013) Effect of Deformation Mode in Prediction of Tire Performance by Dynamic Mechanical Analysis. Rubber World Magazine, 248, 29-35.

[36] Nordsiek, K. (1985) The Integral Rubber Concept-An Approach to an Ideal Tire Tread Rubber. Kautschuk, Gummi, Kunststoffe, 38,178-185.

[37] Moncalero, M., Signetti, S., Mazzanti, B., Bruzzi, P., Pugno, N.M. and Colonna, M. (2017) Effect of Material Elastic Properties and Surface Roughness on Grip Performances of Ski Boot Soles under Wet and Icy Conditions. International Journal of 
Industrial Ergonomics, 61, 62-70. https://doi.org/10.1016/j.ergon.2017.04.004

[38] Eichhorn, S. (2001) The Young Modulus of Microcrytalline Cellulose. Cellulose, 8, 197-207. https://doi.org/10.1023/A:1013181804540

[39] Chung, H., Kong, S. and Kim, D. (2012) Study on the Compressive Modulus of Nylon-11/Silica Nanocomposites. Journal of Nanomaterials, 2012, Article ID: 615489. https://doi.org/10.1155/2012/615489 